\title{
EDITORIAL
}

\section{Environmental exposure in relation to exhaled nitric oxide in newborns: is it all about timing?}

\author{
P. Latzin and U. Frey
}

xhaled nitric oxide (eNO) is a marker of eosinophilic airway inflammation. It is increasingly used for the diagnosis and monitoring of asthmatic lung disease in adults as well as children [1,2] and is believed to be helpful in titrating steroids or in predicting relapse in established asthma $[3,4]$. Although it is known that eNO is increased in healthy atopics [5], its role during the development of asthmatic airway disease is not understood. Only a few studies have examined whether eNO is already elevated before the occurrence of respiratory symptoms or in children that are prone to developing asthma [6, 7]. Data published so far showed an interaction with smoke exposure, suggesting that, at least in high-risk children, eNO may play a role in the very initial phases of recurrent respiratory symptoms [6]. It is tempting to speculate that eNO is a pre-existing marker before allergic inflammation of the airways occurs and that children can be "eNO phenotyped" early in life [8], enabling the identification of those with a high risk for later asthma development. However, before this can be done it is necessary to understand the natural course of eNO during the time period of fastest lung development, and the influence of external environmental stimuli on this course with possible long-term consequences [9].

In this issue of the European Respiratory Journal, GABRIELE et al. [10] help to understand the issues of smoke exposure, airway symptoms and eNO in healthy infants [10]. GABRIELE et al. [10] examined the effect of pre- and post-natal smoke exposure and respiratory tract infections on eNO measured at age 417 weeks in an unselected birth cohort. They found that compared with unexposed infants, post-natal smoke exposure alone led to an increase in eNO, whereas exposure to smoke both pre- and post-natally led to a sharp decrease in eNO. Interestingly, eNO values in children only exposed to smoke pre-natally were not altered compared with values in nonexposed children. On the basis of their data, GABRIELE et al. [10] concluded that the influence of smoking on eNO depends on the timing of the exposure.

Division of Respiratory Medicine, Dept of Paediatrics, Inselspital and University of Bern, Bern, Switzerland.

STATEMENT OF INTEREST: A statement of interest for P. Latzin can be found at www.erj.ersjournals.com/misc/statements.shtml

CORRESPONDENCE: P. Latzin, Division of Paediatric Respiratory Medicine, University Children's Hospital of Bern, Inselspital, 3010 Bern, Switzerland. Fax: 41316324807. E-mail: philip.latzin@ insel.ch
A clear strength of the study by GABRIELE et al. [10] lies in the detailed information on smoke exposure. Data on smoking habits was gathered prospectively from the point of pregnancy onwards. In contrast to previous studies, this enabled GABRIELE et al. [10] to nicely disentangle the exact effects of pre- and/or post-natal smoke exposure on eNO levels. Although they did not validate the smoking history by cotinine levels, GABRIELE et al. [10] correctly stated that any misclassification would veer towards smoking parents being categorised as nonsmokers and, thus, would have caused the effects of smoking to be underestimated rather than overestimated in their study.

In addition, GABRIELE et al. [10] found that eNO levels were decreased in infants with upper respiratory tract symptoms requiring a visit to a doctor or with lower respiratory tract symptoms. This is in line with studies from other cohorts [11], but has to be interpreted cautiously as symptoms were assessed retrospectively and the effect of age and timing on eNO cannot be determined with this data. One clear weakness of the study by GABRIELE et al. [10] is the fact that infants inspired two breaths of nitric oxide (NO)-free air only on days with an ambient NO of $>10 \mathrm{ppb}$. Using a filter at an arbitrary cut-off close to the group mean eNO may have introduced a nonsystematic error. However, findings in the multivariable analysis adjusted for ambient eNO provide some support that the observed associations are real and not due to methodological issues. Another weakness of the study by GABRIELE et al. [10] is that the sampling procedure does not enable eNO to be adjusted for expiratory flow. Thus, possible changes in expiratory flow as a reason for the differences between groups remain unknown, which is unfortunate, especially given the very small changes in eNO values.

So, why is this study important? It is not the first study showing an influence of smoke exposure or respiratory tract infection on eNO measurements in infants [11], it is not the first study showing different influences of pre- and post-natal smoke exposure on eNO in newborn infants [12], and it is clinically not relevant to show that smoking behaviour or respiratory infections may change eNO values within the magnitude of a few ppb. Furthermore, due to low numbers, GABRIELE et al. [10] could not examine an interaction between pre-natal smoke exposure and maternal asthma on eNO levels, as has been reported previously [12]. However, what makes the study by GABRIELE et al. [10] interesting is that it confirms the increasingly apparent role of timing in addition to intensity of environmental exposure in determining eNO levels [12, 13]. In addition, with the inclusion of this study, these results have 
not only been obtained in three different cohorts, but also by using three different methods of measuring eNO [10, 12, 13]. Even though the raw levels of eNO cannot be compared among the different methods (mean eNO levels of $11 \mathrm{ppb}$ in the study by GABRIELE et al. [10], $17 \mathrm{ppb}$ in the study by FREY et al. [12] and 33 and $42 \mathrm{ppb}$, respectively, in the study by FRANKLIN et al. [13]), the effects of smoke exposure relative to the mean were surprisingly comparable among study groups. The use of different eNO measurement methods is significant for this age group because of the lack of standards available and the disparity from the single-breath method used later in life [14].

Finally, these studies further suggest that eNO is a useful marker to determine effects of isolated post-natal passive smoke exposure, which are usually small and not easily detectable by other lung function tests in this age group. Perhaps passive smoke exposure has a weaker effect on lung mechanics, or perhaps eNO is simply a more sensitive test. As the mechanisms for change in eNO following smoke exposure or respiratory tract infection are not entirely understood, this remains speculative. In contrast to post-natal smoke exposure, isolated maternal smoking during pregnancy has no effects on eNO, even though influences on lung mechanics are well known. Although once again the mechanisms involved are unclear, one could imagine the systemic regulation of growth hormones to be different than that of mediators inducing NOsynthase. Furthermore, this finding may hint at the possibility that inflammatory processes in the airways are induced more efficiently by direct exposure (after birth) than indirectly via the placenta. It is unknown whether the opposing effects related to pre- or post-natal exposure are indeed due to influences mediated via the placenta. However, a very tempting hypothesis for this would be a change in susceptibility of mediators that induce NO-synthase with birth or in general depending on (the correct) timing. This may be based on gene-expression/environment interaction (switching on and off certain genes during critical times of exposure) or on different activities of the three forms of NO synthase during different time phases of pregnancy. Some evidence from animal studies exist for the latter possibility, but studies in humans are limited $[15,16]$.

In any case, the results of the study by GABRIELE et al. [10] lend weight to eNO as a sensitive and relevant measure of the small effects caused by exposures at low levels, as also occurs with other environmental exposures, e.g. air pollution, and confirming data from older children [17]. It is important to have such a measure already available at an early age as lung growth and development are most rapid during this time.

Furthermore, the importance of timing may also hold true for the influence of other environmental exposures on lung development, as is known for the development of allergies. Here it has been shown that, for example, the protective effects of a farm environment are dependent when they occur during pregnancy or the first years of life [18].

Whether it is smoke exposure, air pollution, infections, medication or nutrition, it may not only be important whether an exposure occurs but also when it occurs during lung development. It seems plausible that the same environmental stimulus may have opposite effects depending on when it occurs. This has implications both for understanding lung growth and development as well as clinical management, e.g. when during the course of a disease a certain drug is most effective (or has the least side-effects). These complex environment-timing interactions can only be assessed with larger longitudinal cohort studies, regular measurements of eNO (or of other lung function parameters) and carefully assessed exposures. The effects of various environmental insults and their timing, and probably also the potential interaction with genetic influences, can then be disentangled using appropriate statistical approaches.

Further research is needed before treatment and prevention studies can be planned to determine the value of exhaled nitric oxide-phenotyping, and surely before exhaled nitric oxide can be used in individuals for prediction purposes [8].

\section{REFERENCES}

1 Smith AD, Cowan JO, Brassett KP, Herbison GP, Taylor DR. Use of exhaled nitric oxide measurements to guide treatment in chronic asthma. N Engl J Med 2005; 352: 2163-2173.

2 Taylor DR, Pijnenburg MW, Smith AD, de Jongste JC. Exhaled nitric oxide measurements: clinical application and interpretation. Thorax 2006; 61: 817-827.

3 Pijnenburg MW, Bakker EM, Hop WC, de Jongste JC. Titrating steroids on exhaled nitric oxide in children with asthma: a randomized controlled trial. Am J Respir Crit Care Med 2005; 172: 831-836.

4 Pijnenburg MW, Hofhuis W, Hop WC, de Jongste JC. Exhaled nitric oxide predicts asthma relapse in children with clinical asthma remission. Thorax 2005; 60: 215-218.

5 Franklin PJ, Taplin R, Stick SM. A community study of exhaled nitric oxide in healthy children. Am J Respir Crit Care Med 1999; 159: 69-73.

6 Latzin P, Kuehni CE, Baldwin DN, Roiha HL, Casaulta C, Frey U. Elevated exhaled nitric oxide in newborns of atopic mothers precedes respiratory symptoms. Am J Respir Crit Care Med 2006; 174: 1292-1298.

7 Moeller A, Diefenbacher C, Lehmann A, et al. Exhaled nitric oxide distinguishes between subgroups of preschool children with respiratory symptoms. J Allergy Clin Immunol 2008; 121: 705-709.

8 de Jongste JC. To wheeze or not to wheeze: prospective FENO-typing in early infancy. Am J Respir Crit Care Med 2006; 174: 1281-1282.

9 Bush A. COPD: a pediatric disease. COPD 2008; 5: 53-67.

10 Gabriele C, Asgarali R, Jaddoe VW, Hofman A, Moll HA, de Jongste JC. Smoke exposure, airway symptoms and exhaled nitric oxide in infants: the Generation R Study. Eur Respir J 2008; 32: 307-313.

11 Franklin PJ, Turner SW, Hall GL, Moeller A, Stick SM. Exhaled nitric oxide is reduced in infants with rhinorrhea. Pediatr Pulmonol 2005; 39: 117-119.

12 Frey U, Kuehni C, Roiha $H$, et al. Maternal atopic disease modifies effects of prenatal risk factors on exhaled nitric oxide in infants. Am J Respir Crit Care Med 2004; 170: 260-265. 
13 Franklin PJ, Turner S, Mutch R, Stick SM. Parental smoking increases exhaled nitric oxide in young children. Eur Respir J 2006; 28: 730-733.

14 American Thoracic Society, European Respiratory Society, ATS/ERS recommendations for standardized procedures for the online and offline measurement of exhaled lower respiratory nitric oxide and nasal nitric oxide, 2005. Am J Respir Crit Care Med 2005; 171: 912-930.

15 Shaul PW, Afshar S, Gibson LL, et al. Developmental changes in nitric oxide synthase isoform expression and nitric oxide production in fetal baboon lung. Am J Physiol Lung Cell Mol Physiol 2002; 283: L1192-L1199.
16 Sheffield M, Mabry S, Thibeault DW, Truog WE. Pulmonary nitric oxide synthases and nitrotyrosine: findings during lung development and in chronic lung disease of prematurity. Pediatrics 2006; 118: 1056-1064.

17 Fischer PH, Steerenberg PA, Snelder JD, van Loveren H, van Amsterdam JG. Association between exhaled nitric oxide, ambient air pollution and respiratory health in school children. Int Arch Occup Environ Health 2002; 75: 348-353.

18 Riedler J, Braun-Fahrlander C, Eder W, et al. Exposure to farming in early life and development of asthma and allergy: a cross-sectional survey. Lancet 2001; 358: 11291133. 